\title{
APARECIMIENTO Y FETICHISMO: LA CIENCIA DE LA LÓGICA EN LA CRITICA DE MARX AL CAPITAL
}

\author{
Oscar Pérez Portales ${ }^{1}$ \\ Agemir Bavaresco ${ }^{2}$
}

\begin{abstract}
Resumen:
El presente artículo se inserta en la evaluación de la influencia de la Ciencia de la Lógica de Hegel, en la maduración de la Crítica al Fetichismo expuesta por Marx en Capítulo primero de El Capital. La Critica al Fetichismo es una importante llave de lectura del conjunto de la obra marxiana y de abordaje de la ontología de la praxis que entraña su decurso teórico-argumentativo. Dialogamos críticamente con las interpretaciones más actuales que asumen la asunción de la herencia hegeliana en El Capital, restricta a la construcción de un método de exposición y que interpretan el Fetichismo como manifestación fenomenológica. Frente a ello visamos la demostración de la influencia de la Lógica de Hegel en la construcción del Fetichismo como método de crítica de las apariencias. A partir de ello el Fetichismo y su crítica deja de ser simplemente la constatación de un proceso ontológico, propio de la producción capitalista de mercancías y se comporta como método lógico de exposición de la esencia del proceso de producción negado en el intercambio. El presente trabajo parte del estudio de la evolución del tratamiento marxiano de la cuestión del Fetichismo enfatizando su transformación en método de reflexión a partir del encuentro con la Ciencia de la Lógica. En vista de ese objetivo realizaremos una reconstrucción la Teoría del Aparecimiento propia de la Doctrina de la Esencia de Hegel. Más precisamente nos enfocamos en los acápites sobre Existencia, Cosa y Propiedades de la Sección Segunda de la Doctrina de la Esencia. Luego reconstruimos el paralelismo de esta, con la lógica reflexiva aplica por Marx al proceso de producción de la mercancía en el Capítulo Primero de El Capital.
\end{abstract}

Palabras llaves: Aparecimiento. Fetichismo. Lógica hegeliana. Sujeto.

\section{APPEARANCE AND FETISHISM: THE SCIENCE OF LOGIC IN MARX'S CRITIQUE OF CAPITAL}

\begin{abstract}
:
This article is inserted in the evaluation of the influence of the Science of Logic of Hegel, in the maturation of the Critique of Fetishism exposed by Marx in the First Chapter of Capital. The Criticism of Fetishism is an important key to reading the whole of the Marxian work and addressing the ontology of the praxis that entails its theoretical-argumentative course. We critically dialogue with the most current interpretations that assume the assumption of the Hegelian heritage in The Capital, restricted to the construction of a method of exposition and that interpret Fetishism as a phenomenological manifestation. Faced with this, we are looking at the demonstration of the influence of Hegel's Logic in the construction of Fetishism as a method of criticism of appearances. From this, Fetishism and its criticism cease to be simply the verification of an ontological process, typical of the capitalist production of goods and behaves as a logical method of exposing the essence of the production process denied in the exchange. The present work starts from the study of the evolution of the Marxian treatment of the question of Fetishism, emphasizing its transformation into a method of reflection from the encounter with the Science of Logic. In view of this objective, we will make a reconstruction Theory own appearance of the Doctrine of Essence of Hegel. More precisely we focus on the sections on Existence, Thing and Properties of the Second Section of the Doctrine of Essence. Then we reconstruct the parallelism of this, with the reflexive logic applied by Marx to the process of production of the merchandise in the First Chapter of Capital.
\end{abstract}

Keywords: Appearance; Fetishism; Hegelian Logic; Subject.

1 Doutorando do PPG-Filosofía PUCRS. Pesquisa financiada pela Coordenação de Aperfeiçoamento de Pessoal de Nível Superior (CAPES). http://lattes.cnpq.br/6292695504185486. http://orcid.org/000000021817-5162. E-mail: oscarahportales2487@gmail.com.

2 Professor Programa de Pós-Graduação em Filosofia PUCRS. https://orcid.org/0000-0002-7967-4109 CV: http://lattes.cnpq.br/6597683266934574. E-mail: abavaresco@ pucrs.br. 


\section{Introducción}

El presente trabajo evalúa la influencia de la Ciencia de la Lógica de Hegel, en la crítica al Fetichismo expuesta por Marx en El Capital. Tal crítica resulta una importante llave de lectura del conjunto de la obra marxiana y en especial de la ontología de la praxis que entraña su decurso teórico-argumentativo. El tratamiento del Fetichismo dentro de la obra marxiana ha sido objeto de un debate contemporáneo en torno al papel secundario otorgado al uso de esta categoría. Las valoraciones de la logicidad sistémica de El Capital situaron el fetichismo como descripción fenomenológica anexa del proceso de producción del capital. Dentro de la tradición marxista leninista fue obviado como rezago capitalista a ser superado. Al tiempo que en la tradición estructural fue analizado en tanto limitación filosófico humanista dentro del sistema lógico marxiano. Caso ejemplar, el análisis de Althusser lo obvia por ser rezago no científico del enfoque de Marx, fenómeno complementario de la forma valor ${ }^{3}$.

No obstante, el debate alemán de la década de los 60 del siglo XX rescata la centralidad de esta cuestión. Este tiene punto de inspiración en la reflexión de Adorno que analiza el fetichismo de la mercancía como proceso de subordinación abstracta de la realidad, en la colonización y reificación del territorio y del trabajo humano ${ }^{4}$. En su comprensión el fetichismo es parte de la imposición naturalizada de la ley del valor al control de los procesos de producción de subjetividad. Continuador de este enfoque, el movimiento de Neue Marx-Lektüre aporta una interpretación lógica del fetichismo, como parte del proceso de producción y no como fenómeno aislado de este ${ }^{5}$. Esta reconstrucción permitirá valorar el potencial crítico de la Teoría del Valor de Marx, sin el cual podría situarse en la órbita substancialista de la teoría del valor ricardiana. Elemento de vital importancia si valoramos que la determinación substancial de la economía y su relación con la política se sostuvo, en parte, en la renuncia al uso del

ALTHUSSER, Louis. Lire le Capital. Quadrige, Paris, 1996.

"Lo que hace intercambiable a la mercancía es la unidad del tiempo de trabajo abstracto socialmente necesario. El trabajo es abstracto porque, a través de la re-ducción a la unidad, se abstrae de los valores de uso y de las necesidades". ADORNO, Theodor W. Theodor W. Adorno sobre Marx y los conceptos fundamentales de la teoría sociológica. A partir de los apuntes del seminario del semestre de verano de 1962. Constelaciones. Revista de Teoría Crítica, 2017.p.424. Al decir de Marx: La igualdad de trabajos toto cælo [totalmente] diversos sólo puede consistir en una abstracción de su desigualdad real, en la reducción al carácter común que poseen en cuanto gasto de fuerza humana de trabajo, trabajo abstractamente humano. MARX, K. O capital: crítica da economía política. São Paolo: Boitempo. 2013.p.149.

5 BELLOFIORE Riccardo; REDOLFI RIVA Tommaso. The Neue Marx-Lektüre Putting the critique of political economy back into the critique of society. Radical Philosophy 189, jan/feb. 2015. p. 24 .

\begin{tabular}{|c|c|c|c|c|}
\hline Repita Alolectus & Ano 9 & n. 19 & Agosto - Dezembro 2020 & p. $51-72$ \\
\hline
\end{tabular}


fetichismo como método crítico ${ }^{6}$. Tal déficit impidió entender la producción de valor en cuanto proceso subjetivo de producción de la objetividad humana.

Ante este contexto problemático no resulta casual la revalorización de la Teoría del Fetichismo, como centro crítico de la filosofía inmanente a El Capital. Esta revalorización encuentra en el estudio de los nexos entre la exposición marxiana y la Ciencia de la Lógica de Hegel, un centro de desarrollo indispensable. Este análisis de la obra de Marx desde la perspectiva de la Ciencia de la Lógica aporta a la fundamentación del fetichismo como método de crítica de la apariencia. Ello en su dupla función, critica del carácter aparencial de los fenómenos productivos capitalistas y de las categorías de la Economía Política ${ }^{7}$.

En nuestro análisis fundamentamos que la exposición marxiana de la subsunción de las relaciones de producción en las mercancías se encuentra marcadamente influenciada por la comprensión de la Ciencia de la Lógica de Hegel. No solo en el interés de una tesis hermenéutica sino, porque a partir de ello el fetichismo pode ser conceptualizado como método lógico de exposición del proceso social de producción. Esta distinción resulta explorable desde el examen de la Doctrina de la Esencia de Hegel y su influencia en la estructuración del método de crítica de la apariencia de Marx.

Inicialmente articularemos la evolución del tratamiento marxiano de la cuestión del fetichismo en los diversos usos del término, visando enfatizar la problematización y complejidad sistémica que cobra, al encuentro de la Ciencia de la Lógica, en el propio Marx. En vista de ese objetivo realizaremos una reconstrucción de la Teoría del Aparecimiento propia de la Doctrina de la Esencia de Hegel. Dada su amplitud nos centraremos en el análisis de los acápites sobre Existencia, Cosa y Propiedades de la Sección Segunda de la Doctrina de la Esencia. En tanto nuestro objetivo, más que explicitar la relación entre aparecimiento y fetichismo, pretende demostrar que su explicitación final es el resultado de una procesualidad reflexiva ${ }^{8}$. A partir de ello valoramos la lógica reflexiva que Marx aplica en la redacción del primer capítulo de El Capital. Orientados a demostrar el paralelismo de esta lógica argumentativa con la teoría del aparecimiento de Hegel. Esta valoración sería productiva a la superación de las interpretaciones que al asumir el Fetichismo desde la idea fenomenológica lo han

6 KOHAN, Néstor; GOPEGUI, Belén. Nuestro Marx. La Oveja Roja, 2013.

7 BACKHAUS, Hans Georg, 'On the Dialectics of the Value Form', Thesis Eleven, no. 1, 1980, pp.94119. p.95.

8 MOSELEY, Fred; SMITH, Tony (Orgs.). Marx’s Capital and Hegel's Logic: a re-examination. Leiden; Boston: Brill, 2014.

\begin{tabular}{|l|l|l|l|l|}
\hline Ronita & Ano 9 & n. 19 & Agosto - Dezembro 2020 & p. $51-72$ \\
\hline
\end{tabular}


restringido a manifestación del capitalismo. Ello no ha permitido su desarrollo en tanto base de crítica de la realidad humana y más, como método de crítica de la ciencia económica y política?

\section{Fetichismo: fenómeno o modelo analítico.}

La utilización del término y el tratamiento a la problemática del Fetichismo por parte de Marx aparece desde sus reflexiones de juventud. Esta se encuentra unida a la crítica de la idolatría como práctica religiosa reíficante de lo humano ante el tótem religioso. El principio de crítica del Fetichismo se basa en la anteposición de la vida y la comunidad al fetiche religioso. Práctica donde el tótem religioso oculta la relación social que explota la vida humana sacrificada. Esta formulación guarda todavía la esencia de una construcción subjetiva de carácter religioso mas, enuncia la problemática de la socialidad basada en ritos de ocultación del sacrificio de la vida humana. En esta línea la imagen del Moloch ammonita aparece en su tesis doctoral de 1841, como figura idolátrica a la que son sacrificados el trabajo y vida humanas. No obstante, a partir de su utilización en 1842 hace referencia explícita a dos procesos conjuntos, es visto como resultado del trabajo humano y relación de poder autónoma sobre los cuerpos de los productores ${ }^{10}$.

En sus manuscritos de 1844, donde ya reconoce la Lógica de Hegel como una revolución teórica, refiere su tarea en los términos de una crítica teológica todavía por realizar. En este momento el fetichismo es valorado en tanto fenómeno de reducción de la vida humana y ocultamiento de las relaciones de trabajo. Así mismo es una tarea de transformación de esa realidad cosificada que se impone al ser humano como poder autónomo. No es esencialmente un proceso económico sino una crítica radical a las idolatrías sociales, propias de una sociedad basada en la alienación del trabajo. Podría señalarse que existe aquí una lectura de las prácticas en las que se administra y reduce el cuerpo humano en función de la obtención de lucro. Apunta Marx sobre el fetichismo:

(...) El capital muerto va siempre al mismo paso y es indiferente a la real actividad individual (...) El obrero sufre en su existencia y el capitalismo en la ganancia de su mamona inerte $(\ldots)^{11}$. La subida de los salarios despierta en

9 “Ahora, es llamativo el hecho de que la tradición marxista no ha seguido desarrollando esta ética del sujeto. En el posterior desarrollo del pensamiento de Marx - y sobre todo en sus análisis del fetichismo - sigue presente, pero también sin una elaboración sistemática. La razón la veo en el hecho de que progresivamente el movimiento socialista entendió el socialismo como meta definitiva de la historia y por eso concibió la transición al socialismo como una acción de transformación institucional, para la cual esta ética parecía irrelevante". HINKELAMMERT, Franz J. Hacia una crítica de la razón mítica. El laberinto de la modernidad. Materiales para la discusión. San José: Arlekin, 2007.p. 33.

10 DUSSEL, Enrique. Las Metáforas Teológicas en Marx. Editorial Verbo Divino. Navarra, 1993.p.55.

11 MARX, Karl. Manuscritos económicos filosófico. Edições 70. Lisboa, 1968. p.103.

\begin{tabular}{|l|c|c|c|c|}
\hline Ponita Dialectus & Ano 9 & n. 19 & Agosto-Dezembro 2020 & p. 51-72 \\
\hline
\end{tabular}


los trabajadores el mismo deseo de enriquecimiento que en el capitalista, mas, sólo lo puede satisfacer mediante el sacrificio de su cuerpo y de su espíritu $(\ldots)^{12}$. (...) El objeto que el trabajo produce, su producto, se enfrenta a él como un ser extraño, como un poder independiente del productor. El producto del trabajo es el trabajo que se ha fijado en un objeto, que se ha hecho cósico ${ }^{13}$.

El uso de la categoría fetichismo en tanto método de crítica, se infiere ya en la Contribución a la Crítica de la economía política de 1859, para explicar las contradicciones que encarna el carácter dual del proceso de trabajo ${ }^{14}$. Proceso individual que implica la represión del carácter social de los productores, consecuencia genética de la producción de mercancía que entraña la concurrencia al intercambio, de ahí que se presente como resultado de la circulación ${ }^{15}$. La crítica antidolátrica sufre aquí un desarrollo lógico, en el que el proceso asume una exposición necesaria al propio sistema categorial que está construyéndose.

\begin{abstract}
Algo que caracteriza al trabajo que crea valor de cambio es que la relación social de las personas se presenta, por así decirlo, invertida, vale decir como una relación social de las cosas [...] Si es correcto decir que el valor de cambio es una relación de personas, hay que agregar empero que es una relación oculta bajo una envoltura cósica material ${ }^{16}$.
\end{abstract}

Será en la redacción del Libro I de El Capital donde queda definido el Fetichismo como proceso de encantamiento, dualidad, subjetivación de la mercancía. Los procesos sociales de producción se invierten, a partir de una imagen cosificada, mistificada, de lo real. Esta perspectiva nos enuncia la progresión del pensamiento de Marx en el entendimiento de la dupla esencia de este fenómeno: proceso alienante del trabajo y dialéctica del pensamiento para exponer la esencia de las relaciones sociales de producción. Es ontología de la producción y dialéctica del análisis necesario de esta. El Fetichismo aborda un fenómeno de falseasión de los procesos de producción, donde las relaciones de trabajo humano son cosificadas en las mercancías y estas son subjetivadas en el intercambio. Es el resultado de un proceso de síntesis que tiene en el intercambio un proceso social irreducible de negación de la diferencia. Como apunta:

12 Ibidem. p.159.

13 Ibidem. p. 116.

${ }^{14}$ RAMAS San Miguel, Clara. Tesis Doctoral. Hacia una teoría de la apariencia: fetichismo y mistificación en la crítica de la economía política de Marx. Madrid, 2015. p.126.

15 MARX, Karl. Contribução à crítica da economía política. Trad. María Helena Barreiro Alves. Martins editores. São Paolo, 1977. p. 97.

16 Ibidem. p.37.

\begin{tabular}{|c|c|c|c|c|}
\hline Q Rovista Dialoctus & Ano 9 & n. 19 & Agosto - Dezembro 2020 & p. $51-72$ \\
\hline
\end{tabular}


Lo misterioso de la forma mercantil consiste sencillamente, pues, en que la misma refleja ante los hombres el carácter social de su propio trabajo como caracteres objetivos inherentes a los productos del trabajo, como propiedades sociales naturales de dichas cosas, y, por ende, en que también refleja la relación social que media entre los productores y el trabajo global, como una relación social entre los objetos, existente al margen de los productores. Es por medio de este quid pro quo [tomar una cosa por otra] como los productos del trabajo se convierten en mercancías, en cosas sensorialmente suprasensibles o sociales ${ }^{17}$.

En este momento analítico es reconocida la influencia de la lectura de la Ciencia de la Lógica de Hegel en la maduración del pensamiento de Marx ${ }^{18}$. La descripción del proceso de producción de la mercancía no solo describe una dialéctica en la que su carácter fetichista es una propiedad más, sino que se desarrolla genéticamente en su determinación. En esta evoluciona claramente una crítica de la apariencia, a partir de un método reflexivo de anteposición de apariencia y esencia. Donde la herencia hegeliana se encuentra en la compresión de la apariencia como realidad, no como simple invención subjetiva ${ }^{19}$. Como era el caso de la utilización del Fetichismo para la crítica de la idolatría religiosa. El Fetichismo en Marx sería así la expresión de un fenómeno existente en la sociedad mercantil. Es un proceso real que se establece como base de una materialidad, el consumidor toma decisiones y establece relaciones materiales a partir de esto. Es una realidad, pero realidad puesta, que niega la esencia de sí misma, el conjunto de relaciones sociales que sustentan la abstracción en el proceso de intercambio ${ }^{20}$. Este no es un problema lógico, ni moral, ni político, es esencialmente ontológico. La respuesta de Marx es la construcción de relaciones sociales donde este sistema de manifieste directamente, una subjetividad nueva.

No obstante, debemos entender también la especificidad de esta categoría como crítica reflexiva de los procesos de producción y de las categorías lógicas en que se expresan. Por ende, como lógica de exposición de esa ontología. Se constituye así en base de su constatación en el pensamiento a través de la crítica a las categorías de la Economía

17 MARX, K. O capital: crítica da economía política. São Paolo: Boitempo. 2013.p.147.

18 ARTHUR, Christopher. La Lógica de Hegel y El Capital de Marx. Fred Moseley Editor Marx’s Method in Capital, Humanities Press: New jersey. USA, 1993.

19 RAMA San Miguel, Clara. Sobre fetichismo y mistificación como formas de apariencia. Una lectura de la crítica de la economía política de Marx. Eu-topías: revista de interculturalidad, comunicación y estudios europeos, ISSN 2174-8454, N. 11, 2016.

20 "De ese modo se presenta la tesis: el fetichismo de las mercancías es la forma de manifestación desfigurada de la propiedad de valor objetivo de una relación de poder y de dominación, precisamente de poder y de dominación de productores privados sobre el trabajo social". IBER, Christian. Elementos da Teoria Marxiana do Capitalismo: um comentário sobre o livro I de O Capital de Karl Marx [recurso eletrônico. Porto Alegre, RS: Editora Fi; EdiPUCRS, 2013.p.115.

\begin{tabular}{|c|c|c|c|c|}
\hline Rovita Dialectus & Ano 9 & n. 19 & Agosto - Dezembro 2020 & p. $51-72$ \\
\hline
\end{tabular}


Política Inglesa. Por ello no puede interpretarse el Fetichismo solo como proceso, fenómeno social descrito tras la explicación del proceso de trabajo en la producción de mercancía. Al mismo tiempo que Marx precisa la esencia de la cosa mercancía está aplicando una doctrina reflexiva, que es también parte de un método de análisis del Fetichismo. Es así complejo separar el proceso de crítica y exposición en que las categorías se desarrollan genéticamente de la forma en que son analizadas. El propio Marx deslinda una supuesta interpretación del Fetichismo como anexo, rezago o adición aleatoria a la exposición del proceso de producción de la mercancía:

La reflexión en torno a las formas de la vida humana, y por consiguiente el
análisis científico de las mismas, toma un camino opuesto al seguido por el
desarrollo real. Comienza post festum [después de los acontecimientos] y, por
ende, disponiendo ya de los resultados últimos del proceso de desarrollo. Las
formas que ponen la impronta de mercancías a los productos del trabajo y por
tanto están presupuestas a la circulación de mercancías, poseen ya la fijeza
propia de formas naturales de la vida social, antes de que los hombres procuren
dilucidar, no el carácter histórico de esas formas --que, más bien, ya cuentan
para ellos como algo inmutable-- sino su contenido. (...) Pero es precisamente
esa forma acabada del mundo de las mercancías (...) la que vela de hecho, en
vez de revelar, el carácter social de los trabajos privados, y por tanto las
relaciones sociales entre los trabajadores individuales ${ }^{21}$.

Esta explicación describe una estrategia de análisis de la realidad puesta, necesaria a los momentos conceptuales en los que tiene posibilidad de ser inteligible al pensamiento la esencia de la cosa mercancía. A partir de un método de análisis que cuestiona la presentación de los conceptos puestos, como se manifiestan, la demostración de su contradicción y negación ${ }^{22}$. En cada uno se distingue los momentos de negación, "subsunción” en términos de Marx, suprasunción, como resultado de una necesidad lógica de la demostración de su propia esencia. El Fetichismo explica como las categorías son puestas en la sociedad, como existen en cuanto comprensión de un proceso, mas define que no son lo que aparentan. Por ello han de sufrir un proceso reflexivo que las exponga en cuanto lo que son: relaciones sociales. Para que las categorías que desde el punto de vista formal la exponen, traigan la esencia que esta oculta, negada. Mostrar aquello que las diferencia, frente al "el economista burgués, cuyo limitado cerebro no consigue distinguir, entre forma de manifestación y lo que en ella se manifiesta"23.

21 MARX, K. O capital: crítica da economía política. São Paolo: Boitempo. 2013.p.150.

22 BAVARESCO, Agemir; LARA, Eduardo Garcia. Sistema e silogismo em O Capital. Veritas (Porto Alegre), 2017, vol. 62, no 1, p.12.

23 MARX, K. O capital: crítica da economía política. São Paolo: Boitempo. 2013. p.643.

\begin{tabular}{|l|c|c|c|c|}
\hline Ronita Dialectus & Ano 9 & n. 19 & Agosto-Dezembro 2020 & p. 51-72 \\
\hline
\end{tabular}


Es aquí donde se aprecia que en Marx el tratamiento del Fetichismo no es ya la descripción de un fenómeno. Por el contrario, en su reflexión del proceso de producción de la mercancía aplica una lógica de crítica a las apariencias categoriales. Esa lógica, que supera la formulación del Fetichismo, tiene nexos incuestionables con la herencia hegeliana. A continuación, reconstruiremos la Teoría del aparecimiento, en el tratamiento de la relación entre existencia, cosa y propiedades en el objetivo de establecer su relación con la crítica marxiana al Fetichismo.

\section{Aparecimiento: Existencia, cosa y propiedades.}

La Doctrina de la Esencia se dedica a un objetivo lógico esencial, la Lógica como ciencia del pensar puro, debe dar cuenta de la verdad del pensamiento. Mas, como afirma Federico Orsini en ese proceso debe expresar la inteligibilidad de todas las $\operatorname{cosas}^{24}$. Donde esta indaga reflexivamente lo que hay de negación en esa realidad puesta. Esto significa que la Lógica no es una ciencia del pensamiento puro, ni simplemente un ejercicio del pensar sobre sí mismo, sino un medio para develar el concepto en cuanto lo que es. En este sentido sería para Marx la base de exposición del develamiento de las relaciones sociales, el carácter social de los procesos que han sido ocultados, negados, fantasmagorizados en objetos. El Fetichismo expone así los procesos sociales que están negados en la realidad objetual de la mercancía, el dinero y el capital, como realidades puestas. No en tanto ello es el resultado de una reflexión, de un proceso de transformación crítica del propio pensamiento, a partir de la crítica de las categorías de la Economía Política $^{25}$.

24 A finalidade última de toda a Lógica não é o conceito enquanto tal (o telos da Lógica Objetiva) e sim a unidade absoluta do conceito e da objetividade e, afinal, a unidade do conceito consigo mesmo (telos da Lógica Subjetiva) ORSINI, Federico. A teoria do aparecimento na Lógica de Hegel. POA, 2019.p.3.

25 Como enuncia Marx: "Podría parecer que (...) para hablar de la producción a secas deberíamos o bien seguir el proceso de desarrollo histórico en sus diferentes fases, o bien se aclara desde el comienzo que estamos ante una determinada época histórica, por ejemplo, de la moderna producción burguesa, de la cual es en realidad nuestro tema específico. Pero todas las épocas de la producción tienen ciertos rasgos en común, ciertas determinaciones comunes. La producción en general es una abstracción, pero una abstracción que tiene un sentido, en tanto pone realmente de relieve lo común, lo fija y nos ahorra así su repetición. Sin embargo, lo general y lo común, extraído por comparación, es a su vez algo completamente articulado y que se despliega en distintas determinaciones. Algunas de estas pertenecen a todas las épocas, otras son comunes sólo a algunas. Ciertas determinaciones serán comunes a la época más moderna y a la más antigua. Sin ellas no podría concebirse ninguna producción, pues si los idiomas más revolucionados tienen leyes y determinaciones que son comunes a los menos desarrollados, lo que constituye su desarrollo es precisamente aquello que los diferencia de estos elementos generales comunes". MARX, K. Elementos fundamentales para la crítica de la economía política. Borrador 18571858. $15^{\text {a }}$ Ed. Madrid: Siglo XXI. 1987. p.56.

\begin{tabular}{|c|c|c|c|c|}
\hline Revista Dialectus & Ano 9 & n. 19 & Agosto - Dezembro 2020 & p. $51-72$ \\
\hline
\end{tabular}


Al interés de nuestra indagación resulta central fijar el momento de pasaje, del cuestionamiento de Hegel en La Ciencia de la Lógica, de la relación entre fundamento y condición para la existencia. Como resultado de la necesidad lógica de exponer el momento en que la cosa no es un objeto de reflexión, sino que emerge en su existencia ${ }^{26}$. El inicio de la Sección Segunda ya nos dice cuál es la necesidad lógica, la esencia tiene que aparecer. Desarrollo que tiene como punto de partida la transformación del ser en esencia. Dicho pasaje nos enuncia que la simple exposición de condición y fundamento no ha hecho más que suprasumir el segundo para instaurar la necesidad lógica del aparecimiento de la esencia. El fundamento es fundamento de la existencia. La existencia es un ser puesto, ello enuncia que la reflexión deberá asumir su inmediatidad, como realidad puesta.

Así, la esencia aparece (erscheint). La reflexión es el aparecer (Scheinen) de la esencia dentro de ella misma. Las determinaciones de esta, encerradas en la unidad, son pura y simplemente apenas como puestas, suprasumidas; o sea, ellas es la esencia inmediatamente idéntica a si dentro de su ser puesto ${ }^{27}$.

El Erscheinen es el resultado de un proceso de progresión en tanto unidad de

la esencia con su inmediatidad. La cosa o existente en ese momento extingue su negatividad. En tanto la cosa contiene su reflexión, el fundamento esta como suprasunción de la reflexión de la cosa que esta puesta. La extinción inicial de la negatividad hace que la apariencia deba completarse hasta su aparecimiento. El aparecimiento es la materialidad de un proceso reflexivo donde la apariencia de la esencia es un resultado del pensamiento. En primer lugar el aparecimiento es simple unidad de la esencia con la inmediatidad del ser. Por ello en el aparecimiento primero, existente, cosa, la esencia no está explícitamente presente ${ }^{28}$. La existencia es además aparecimiento, entendido en el sentido de la verdad de la cosa en sí. Por ello reflexiona Hegel:

La verdad del ser no es la de ser un primero inmediato, mas si de ser la esencia que surgió en la forma de la inmediatidad. (...) Pues la existencia es la inmediatidad que surgió del suprasumir de la mediación que relaciona a través

26 IBER, Christian. Fundamento, condição e existência. Inédito. POA, 2019.p.4.

27 HEGEL, Georg Wilhelm Friedrich. Ciencia Da Lógica: 2. A Doutrina da Essencia. Trad. Cristhian G. Iber; Federico Orsini. Petropolis, Rj: Vozes; Bragança Paulista, Sp: Editora Universitária São Francisco, 2017.p.133.

28 IBER, Christian. A passagem para a $2^{\mathrm{a}}$ seção da lógica da essência: o aparecimento. Inédito. POA, 2019.p.2.

\begin{tabular}{|l|l|l|l|c|}
\hline Renista & Ano 9 & n. 19 & Agosto-Dezembro 2020 & p. 51-72 \\
\hline
\end{tabular}


del fundamento y de la condición, inmediatidad que, en el surgir, suprasume justamente ese propio surgir ${ }^{29}$.

Podemos adelantar que dicha lógica es identificable en Marx en el análisis del proceso de producción. Ante el poner inmediato de la esencia de la mercancía en la necesidad, advierte que esta no puede ser la esencia de la mercancía como cosa. Pues consiste en una negatividad exterior resultado de una reflexión subjetiva. El proceso de realización de la mercancía como satisfactor no está determinado. Es indispensable que la inmediatidad de la mercancía sea determinada. En la línea de Hegel el saber debe asumir su falencia en cuanto al conocimiento de lo inmediato, que no puede ser asumido como esencia de la existencia. Contradicción que nos deja ante la necesidad lógica de indagar más allá de la inmediatidad de la existencia. Pues lo inmediato ha negado las mediaciones y las determinaciones. En este proceso la reflexión tendría como fin de su suprasumir un resultado que es diferente del saber positivo de la esencia.

En el análisis de la Lógica de Hegel es importante señalar que no hay en esta comprensión un esencialismo o inmanentismo, donde la esencia permanecería dando condición de predicación a la existencia. Fundamentación en la cual existencia sería una falsa realidad. Por el contrario, en la existencia se encuentra la esencia en cuanto la existencia es su exteriorización, su venir al aparecer. La esencia aquí es un fundamento que no se diferencia de su fundamentado. La existencia es el fundamento reflexionado, es el fundamento de la esencia que se exteriorizó. Este es un elemento central para comprender, en otra llave de lectura, la evolución que a partir de la Contribución a la crítica de la Economía Política tiene el tratamiento de Marx sobre el Fetichismo. A partir de ese momento no es más una falsedad ideológica, propia de su etapa de crítica de la idolatría religiosa. La realidad fetichista de la mercancía, su idolatría, no demuestra o determina carácter no objetivo. En ese sentido sentencia Hegel:

Así, la existencia no debe ser tomada aquí como un predicado o una determinación de la esencia, de modo que una proposición sobre eso rezaría: "la esencia existe o tiene existencia", mas, antes, la esencia paso para la

29 HEGEL, Georg Wilhelm Friedrich. Ciencia Da Lógica: 2. A Doutrina da Essencia. Trad. Cristhian G. Iber; Federico Orsini. Petropolis, Rj: Vozes; Bragança Paulista, Sp: Editora Universitária São Francisco, 2017.p.135.

\begin{tabular}{|l|c|c|c|c|}
\hline Ronita Dialectus & Ano 9 & n. 19 & Agosto-Dezembro 2020 & p. 51 - 72 \\
\hline
\end{tabular}


existencia; la existencia es su exteriorización absoluta, más allá de la cual la esencia no permanece atrás ${ }^{30}$.

Por ello de lo que se trata es del dualismo de la esencia. La esencia como fundamento de la existencia, y la esencia como existente. La existencia tiene dentro de si las mediaciones. Por ello guarda dentro de sí su negación y se pone a partir de su suprasumir, es un existente o cosa. La esencia es negatividad y mediación, al tiempo que la existencia es ser dentro de sí, cosa (Ding). Por ello debemos continuar el proceso de determinación de la cosa. La contradicción de la existencia en su dupla condición de relación con la esencia se expresa en los siguientes términos:

La existencia, en cuanto existente, esta puesta en la forma de la unidad negativa, que ella es esencialmente. Mas esa unidad negativa es, inicialmente, apenas una determinación inmediata, con eso, el uno de algo en general. Mas el algo existente es diferente del algo que $e^{31}$.

Hegel distingue a continuación la cosa de la existencia, del ser, por el hecho de la primera tener dentro de sí sus mediaciones. Este estatus nos señala que la mediación como interioridad de la $\cos a$, muestra su insuficiencia para determinarse. Debido a que esta relación de mediación con la esencia, a partir de su interioridad, marca el carácter inmediato de su mediación, su singularidad. Lo que existe en la concreción de su reflexión es diferente de lo que es. Es parte de un ser general que no ha sido expuesto desde su inmediatidad. Como resultado de la reflexión de su mediación en ella misma, es solo el uno de un algo general.

La existencia tiene en ella la "diferencia de la cosa en sí y de la existencia externa". Mas, no como un pasaje de una forma en otra, si no que contiene estos dos momentos como mediaciones propias. Ello sería desde el punto de vista lógico importante para analizar que la relación entre existencia y esencia no debe tomarse como un dato fenomenológico. Como una relación de identidad entre una identidad auténtica y un fenómeno falseable. Esta visión de Hegel reconoce que lo existente y la cosa son parte de una mediación de la existencia. En términos de Hegel:

30 HEGEL, Georg Wilhelm Friedrich. Ciencia Da Lógica: 2. A Doutrina da Essencia. Trad. Cristhian G. Iber; Federico Orsini. Petropolis, Rj: Vozes; Bragança Paulista, Sp: Editora Universitária São Francisco, 2017.p.138.

31 Ibidem.p.138.

\begin{tabular}{|l|c|c|c|c|}
\hline Q Ponista Dialectus & Ano 9 & n. 19 & Agosto-Dezembro 2020 & p. 51-72 \\
\hline
\end{tabular}


La cosa es diferenciada de su existencia, como algo puede ser diferenciado de su ser. (...) porque la existencia tiene el momento de la mediación en ella misma (...) y la existencia como tal contiene esa propia diferenciación dentro del momento de su mediación. La diferenciación de la cosa en sí y de la existencia externa ${ }^{32}$.

Puede afirmarse que esta comprensión lógica es identificable en Marx cuando interpreta que el Fetichismo de la mercancía no es un proceso de descubrimiento de una realidad fenoménica, falsa, ideológica, proceso subjetivo que esconde una substancia verdadera. Por el contrario, desde el punto de vista de la reflexión, lo que enuncia el Fetichismo es la mediación de un proceso que es propio de la existencia de la mercancía, donde cosa en sí y existencia son momentos de un proceso inscrito en lo real.

Hegel ha demostrado la diferencia de la existencia y la cosa como partes indisolubles, relacionales, no predicativas de la existencia. Ello es un presupuesto lógico anti substancial y relacional, que aplicado a una crítica del proceso de producción podría aportar llaves de lecturas de la crítica marxiana al Fetichismo. Al demostrar esta como paso lógico donde se muestra un proceso relacional entre lo existente y la existencia como esencia negada en su mediación propia. Mas, cómo establecer entonces, dentro del decurso que hace aparecer la esencia, la determinación de la cosa en sí y su relación con la existencia externa. Hegel inicia con una definición:

\footnotetext{
La cosa en si es el existente como inmediato esencial, presente a través de la mediación suprasumida. En eso, la mediación es igualmente esencial para la cosa en si; mas esa diferencia, en esa existencia primera o inmediata, se separara en determinaciones indiferentes. Un lado, a saber. La mediación de la cosa, es su inmediatidad no reflejada, por tanto, su ser en general, el cual, por estar, al mismo tiempo, determinado como mediación, es un ser ahí otro a sí mismo, múltiple dentro de sí y externo ${ }^{33}$.
}

Dentro de la cosa se muestra la reflexión entre lo esencial y lo inesencial, como necesidad lógica para la comprensión de la cosa en sí y su relación con la existencia externa. En este análisis lo inesencial está referido al ser mediado de la cosa. Del cual la cosa en sí (inmediato esencial) es la base, no su fundamento. Precisa Hegel el estatus de la cosa en sí:

\begin{tabular}{|l|c|c|c|c|}
\hline Govista Dialectus & Ano 9 & n. 19 & Agosto-Dezembro 2020 & p.51-72 \\
\hline
\end{tabular}




\begin{abstract}
Por eso, también la reflexión en cuanto ser ahí que se media a través del otro, cae fuera de la cosa en sí. Esa no debe tener ninguna multiplicidad determinada en sí misma, y la obtiene solamente por ser traída a la reflexión exterior, mas permanece indiferente frente a la multiplicidad (La cosa en si tiene color solamente si es traída a los ojos, tiene sabor si esta traída a la nariz etc.). Su diversidad son consideraciones que otro lleva en cuneta relaciones determinadas que ese se da para con la cosa en sí, e que no son determinaciones propias de la misma ${ }^{34}$.
\end{abstract}

Sin embargo, la determinación de esta multiplicidad exterior es una necesidad lógica de la reflexión. La cosa en sí no puede estar determinada por la relación de exterioridad de la cual derivaría en una multiplicidad. Es decir, la cosa en sí, lo inmediato esencial, no se realizaría si se tiene en cuenta su multiplicidad exterior. Por tal razón deberá determinarse su esencialidad, sus multiplicidades exteriores, acertar cuál es la condición de determinación que posibilita la relación por externalidad de las cosas con lo otras y consigo misma. Dicha reflexión es precisamente el ámbito del sujeto que se relaciona con la externalidad de estas cosas. Los productores con las mercancías como externalidades. Por tanto, emerge la necesidad lógica de la reflexión sobre la existencia de esta exterioridad múltiple y la cosa en sí:

\begin{abstract}
Pues esa existencia es solamente externa, en la medida en que ella se relaciona con la identidad esencial como con un otro. La multiplicidad no tiene, por tanto, además de la cosa en sí, un subsistir autosubsistente propio, mas es solamente como apariencia frente a esa, en su relación necesaria con ella, como el reflejo que se rompe en ella. La diversidad está presente, por tanto, como la relación de otro con la cosa en sí; con todo, ese otro no es nada subsistente pro sí, mas es solamente como relación con la cosa en sí; al mismo tiempo, no obstante, él es solamente o repeler esa cosa; él es así, el contra choque insubsistente de si dentro de sí mismo ${ }^{35}$.
\end{abstract}

La multiplicidad de cosas en sí, que solo se relaciona a partir de una exterioridad no tiene un subsistir esencial en ese relacionar. Podríamos adelantar la similitud con este análisis que guarda la exposición marxiana del proceso de cambio. La diversidad de mercancías intercambiables con sus múltiples exterioridades, dependiendo de las relaciones con otras cosas en sí, no expresa la determinación que permita explicar su esencia y su relación con el exterior. Por tanto, continuando la reflexión hegeliana, cuál es esta condición de determinación que posibilita la relación por externalidad de las cosas con lo otras y consigo misma. Debemos recordar que aquí la reflexión externa

\begin{tabular}{|l|c|c|c|c|}
\hline Govista Dialectus & Ano 9 & n. 19 & Agosto-Dezembro 2020 & p.51-72 \\
\hline
\end{tabular}


comporta el término de unidad de las cosas en sí en su externalidad. Reflexión que precisamente se constituye el ámbito del sujeto que se relaciona con la externalidad de estas cosas. En la lógica de Marx los productores con las mercancías como externalidades. Mas, estas no son determinaciones esenciales pues no expresan su esencialidad determinada. Para Hegel se resuelve en estos términos:

\begin{abstract}
Ambas cosas en sí, las cuales deben constituir los extremos de la relación, coinciden, de facto, en un; y solamente en una cosa en sí que, en la reflexión externa, relacionase consigo misma, y aquello que constituye su determinación es su relación propia consigo como con el otro. Esta determinación es la propiedad de la cosa ${ }^{36}$.
\end{abstract}

Precisamente por la propiedad la cosa se identifica como tal, una vez esta ha sido determinada. Esta se presupone como diferente de la reflexión. Es su negación. La propiedad es cualidad reflexionada que en su dupla condición es distinguida de la cosa y su existencia externa pero al mismo tiempo está relacionada con ella.

La cosa en si abstracta es ella misma, esa relación que retorna para dentro de sí a partir de otro; ella está, a través de eso, determinada en sí misma; mas su determinación es constitución, la cual, como tal, es, ella misma, determinación, y, como relacionar como el otro, no para el ser otro y está sustraída de alteración ${ }^{37}$.

La propiedad es apenas una superficie en la que se realiza el ser de la cosa, mas ella no desparece en ese devenir. Las propiedades de la cosa no son el mero resultado de la relación de externalidad con otra cosa. Por el contrario, son al mismo tiempo sus propias determinaciones. Por lo que esta puede ser entendida de una forma, lo que permite su definición en cuanto cosa. Hegel insiste en no situar la cosa en sí como una sustancialidad sino, como una situación que se mueve en el espacio de determinación de la cosa: “(...) ella no es una base sin determinación situada más allá de su existencia externa, pero si está presente dentro de sus propiedades como fundamento"38.

Es interesante como el desdoblar de la cosa describe una pauta procesual de necesidad auto-sustentada que puede ser identificada en la descripción de Marx sobre la producción de mercancías. La Teoría del Aparecimiento no se detiene en este recorte 
seleccionado. No obstante en él pueden identificarse elementos que aportan a una valoración del método usado por Marx. Como hemos evidenciado en Hegel la crítica a la apariencia y la posibilidad del pensamiento de acceder a la esencia de la realidad, se sustentan en una sólida estructura reflexiva. Esto es, la relacionalidad y auto-subsistencia genética al interior de las categorías, rechaza cualquier sistema formal que viene a intervenir la necesidad lógica del movimiento que el pensamiento debe describir.

Esta es la revolución que el joven Marx reconoce en Hegel $^{39}$. Como hemos señalado esta se constituye en base del cambio superador que el tratamiento del Fetichismo tiene en la redacción del Capital frente a los primeros abordajes del fenómeno por Marx. A continuación, nos centraremos en demostrar los nexos de la crítica de Marx al carácter fetichista de la mercancía con la lógica expuesta por Hegel en la Teoría del Aparecimiento. Valoraremos el desarrollo de las categorías propias de la producción de mercancía a las que somete a una reflexión que permite distinguir un método de análisis de herencia hegeliana. Al contrario de enfocarnos en el Epígrafe 4 del Capítulo 1, del Libro Primero, donde Marx expone la esencialidad del fetichismo como fenómeno.

\section{Aparecimiento y Fetichismo como crítica de la apariencia.}

En el estudio del proceso de producción de la mercancía y su carácter fetichista, Marx sigue la lógica hegeliana de diferencia entre la esencia y la existencia. En el sentido de que el conjunto de determinaciones esenciales de la cosa puede ser abstraída para ser esencia puesta (conocida). El estudio del Capital enuncia la herencia en Marx de la Lógica de la Doctrina de la Esencia de Hegel. En tanto la compresión hegeliana de la existencia, como esencia puesta, no inmanente sino, resultado de la reflexión, es básica para su crítica de la visión iusnatural de las categorías de la Economía Política $^{40}$. Donde no se impone una formalización externa a la realidad sino, que su reflexión se desarrolla a través de una necesidad lógica que se evidencia en la exposición genética de las categorías. Esta exposición es movida por una formulación que expone la contradicción inherente de cada categoría. Lógica reflexiva que se evidencia en la procesualidad dialéctica con la cual Marx explica el proceso de producción de la

39 MARX, Karl. Manuscritos económicos filosófico. Edições 70. Lisboa, 1968. p.103.

40 MOSELEY, Fred; SMITH, Tony (Orgs.). Marx's Capital and Hegel's Logic:a reexamination. Leiden; Boston: Brill, 2014. p.218.

\begin{tabular}{|l|l|l|l|l|}
\hline Q Povista Dialectus & Ano 9 & n. 19 & Agosto-Dezembro 2020 & p.51-72 \\
\hline
\end{tabular}


mercancía como cosa que es en primer lugar una cosa ante una reflexión exterior. En la exposición del proceso de producción de la mercancía inicia Marx:

Nuestra investigación, por consiguiente, se inicia con el análisis de la mercancía. La mercancía es, en primer lugar, un objeto exterior, una cosa que merced a sus propiedades satisface necesidades humanas del tipo que fueran ${ }^{41}$.

La mercancía en cuanto cosa material con propiedades tiene su fundamento en la satisfacción de la necesidad. Sin embargo luego apunta Marx que esta es solo una determinación simple pues nada nos dice de las condiciones en las cuales ella realiza esa satisfacción. En el caso de la producción se trata del sujeto que produce, el trabajo, la naturaleza y el instrumento de trabajo, así como el trabajo acumulado. Este nivel abstracto no es el histórico real. Lo cual no quiere decir que sea irreal sino, que su esencia es puesta, en este caso es un fenómeno, existencia de la cual la esencia se encuentra a un nivel más profundo de determinaciones. Objetivo para el cual Marx parte de criticar este carácter de realidad puesta de la mercancía:

Toda cosa útil, como el hierro, el papel, etc., ha de considerarse desde un punto de vista doble: según su cualidad y con arreglo a su cantidad. Cada una de esas cosas es un conjunto de muchas propiedades y puede, por ende, ser útil en diversos aspectos. La utilidad de una cosa hace de ella un valor de uso. Pero esa utilidad no flota por los aires. Está condicionada por las propiedades del cuerpo de la mercancía, y no existe al margen de ellas. El cuerpo mismo de la mercancía, tal como el hierro, trigo, diamante, etc., es pues un valor de uso o un bien ${ }^{42}$.

Por ello ante el poner inmediato Marx advierte que la necesidad no puede ser la esencia de la mercancía como cosa. Pues consiste en una negatividad exterior resultado de la reflexión subjetiva. El proceso de realización de la mercancía como satisfactor no está determinado. Es indispensable que la inmediatidad de la mercancía sea determinada. En la línea de Hegel el saber debe asumir su falencia, en cuanto el conocimiento de lo inmediato no puede ser asumido como esencia de la existencia. Esa contradicción nos deja ante la necesidad lógica de indagar más allá de esa inmediatidad de la existencia. Pues lo inmediato ha negado las mediaciones y las determinaciones. Proceso para el cual la reflexión tendría como fin de su suprasumir un resultado que es diferente del saber

41 MARX, K. O capital: crítica da economía política. São Paolo: Boitempo. 2013.p.113.

42 MARX, K. O capital: crítica da economía política. São Paolo: Boitempo. 2013.p.114.

\begin{tabular}{|l|c|c|c|c|}
\hline Rovita Dialeatus & Ano 9 & n. 19 & Agosto-Dezembro 2020 & p. 51-72 \\
\hline
\end{tabular}


positivo de la esencia. Es así que el saber positivo de la esencia volvería a responder por la mediación, ir al fondo de la mediación en palabras de Hegel. La mediación y su exposición es el momento esencial de lo existente. En Marx esta mediación proviene de un proceso de interacción social.

Continuando la herencia Hegeliana la evaluación de Marx expone este proceso como una realidad objetiva. No se trata de que la existencia sea una subjetividad de la cosa, ella tiene un existir real. Elemento que distingue el posicionamiento de Marx en la redacción del Capital a sus posicionamientos juveniles de análisis del Fetichismo religioso $^{43}$. La mercancía es la existencia y es fundamento de una esencia expuesta. No puede ser interpretada fenomenológicamente como representación de una esencia substancial que le da contenido y desde ahí la deja sin sustrato de realidad. No es un fenómeno ideológico que debe ser contestado con una búsqueda de la esencia natural del trabajo. Por el contrario, es resultado de una praxis social. Su ontológica implica esta relación esencial donde la esencia de su fundamento fue suprasumido en una reflexión.

Por tanto, hay una necesidad reflexiva de exponer la esencia de la mercancía como cosa que no se agota en su apariencia como satisfactor de necesidades. Esto es, en lógica hegeliana, exponer la distinción entre la cosa de la existencia y el ser que tiene dentro de si sus mediaciones. Marx evalúa como la mercancía, en cuanto valor de uso que satisface necesidades, se externaliza como valor de cambio. Dupla relacionalidad que expondrá las contradicciones de esta esencia puesta. Así establece la relación entre el valor de uso como negado y el valor de cambio como existente, externalidad de la esencia. En ello se encuentra también la visión hegeliana, anti-substancial y anti-predicativa de la compresión de este proceso. Marx expone:

\begin{abstract}
Este carácter suyo no depende de que la apropiación de sus propiedades útiles cueste al hombre mucho o poco trabajo. (...) Los valores de uso constituyen el contenido material de la riqueza, sea cual fuere la forma social de ésta. En la forma de sociedad que hemos de examinar, son a la vez los portadores materiales del valor de cambio ${ }^{44}$.
\end{abstract}

El valor de uso no expone todas las determinaciones y se encuentra negado en la forma existente de la mercancía, valor de cambio. La mercancía es una cosa, como

43 HENRICH, Michael. Crítica de la economia política. Una introducción a El Capital de Marx. Escolar y Mayo editores. 2008.p.86.

44 MARX, K. O capital: crítica da economía política. São Paolo: Boitempo. 2013.p.114.

\begin{tabular}{|c|c|c|c|c|}
\hline Revita Dinleotus & Ano 9 & n. 19 & Agosto - Dezembro 2020 & p. $51-72$ \\
\hline
\end{tabular}


negación en sí misma. Ella es una determinación inmediata de un grupo de relaciones. Es parte de un ser general que no ha sido expuesto desde su inmediatidad. Al decir de Hegel, como resultado de la reflexión de su mediación en ella misma, es solo el uno de un algo general. La mercancía es un existente en el que lo que existe es diferente de lo que es. El valor de cambio es la existencia externa de la mercancía. Como coloca Marx:

(...) Sin embargo el valor de cambio no puede ser mas que el modo de expresión, la "forma de manifestación" [Erscheinungsfrom] de un contenido que de él puede ser distinguido ${ }^{45}$.

Sin embargo, habría que determinar las múltiples determinaciones inmediatas de esta cosa. La cosa mercancía debe atravesar las determinaciones exteriores para mostrar, en el mismo curso reflexivo hegeliano, la diferencia entre lo esencial y lo inesencial. Marx valora la fragilidad de valorar la mercancía desde la multiplicidad exterior de los valores de cambio. La multiplicidad de características del objeto, así como del trabajo que la crea, harían inviable la realización de la mercancía que solo se realiza en el intercambio. En este caso no por una regla de formalización externa, propia de la economía política; sino porque si distinguidas por la multiplicidad concreta de los valores de uso o la abstracción de los valores de cambios, las mercancías no se realizarían en el proceso de cambio a partir de ser singularidades.

Se observa la necesidad reflexiva de identificar aquella propiedad que hace explícita la esencia de la cosa. Como condición de determinación entre la externalidad de la cosa mercancía con otras y consigo misma. Marx la fundamenta en el trabajo humano indeferenciado (abstracto), que está negado en la externalidad de la mercancía como valor de cambio:

Examinemos ahora el residuo de los productos del trabajo. Nada ha quedado de ellos salvo una misma objetividad espectral, una mera gelatina de trabajo humano indiferenciado, esto es, de gasto de fuerza de trabajo humana sin consideración a la forma en que se gastó la misma. Esas cosas tan sólo nos hacen presente que en su producción se empleó fuerza humana de trabajo, se acumuló trabajo humano. En cuanto cristalizaciones de esa sustancia social común a ellas, son valores ${ }^{46}$.

\begin{tabular}{|l|c|c|c|c|}
\hline Q Povista Dialectus & Ano 9 & n. 19 & Agosto-Dezembro 2020 & p. 51-72 \\
\hline
\end{tabular}


Es interesante como el desdoblar de la cosa, describe una pauta procesual de necesidad auto sustentada, que puede ser identificada en la descripción de Marx sobre la producción de mercancías. Las mercancías a través de su existencia entran en el mercado para ser intercambiadas y alteradas conforme su valor. Pero el proceso de aparecimiento de su esencia como negación de sí misma no es solo un momento de reflexión exterior, sino que se desarrolla a lo largo de su determinación ${ }^{47}$. Esta propiedad que permite el advenimiento de la esencia en la diversidad exterior de la cosa mercancía es el trabajo humano:

\begin{abstract}
A primera vista, una mercancía parece ser una cosa trivial, de comprensión inmediata. Su análisis demuestra que es un objeto endemoniado, rico en sutilezas metafísicas y reticencias teológicas. En cuanto valor de uso, nada de misterioso se oculta en ella, ya la consideremos desde el punto de vista de que merced a sus propiedades satisface necesidades humanas, o de que no adquiere esas propiedades sino en cuanto producto del trabajo humano. (...) El carácter místico de la mercancía no deriva, por tanto, de su valor de uso. Tampoco proviene del contenido de las determinaciones de valor. En primer término, porque por diferentes que sean los trabajos útiles o actividades productivas, constituye una verdad, desde el punto de vista fisiológico, que se trata de fricciones del organismo humano, y que todas esas funciones, sean cuales fueren su contenido y su forma, son en esencia gasto de cerebro, nervio, músculo, órgano sensorio, etc., humanos ${ }^{48}$.
\end{abstract}

Es este descubrimiento, que contesta las formulaciones clásicas de la Economía Política, el que da base a la formulación del Fetichismo como fenómeno de negación del trabajo y la relacionalidad humana. Marx lo sitúa como ley de la negación del trabajo vivo. Es decir, no se agota aquí la exposición del fenómeno:

Lo misterioso de la forma mercantil consiste sencillamente, pues, en que la misma refleja ante los hombres el carácter social de su propio trabajo como caracteres objetivos inherentes a los productos del trabajo, como propiedades sociales naturales de dichas cosas, y, por ende, en que también refleja la relación social que media entre los productores y el trabajo global, como una relación social entre los objetos, existente al margen de los productores ${ }^{49}$.

Arribar a dicha conclusión será el resultado de someter a análisis reflexivo y dialectico el trabajo como propiedad. No obstante, este estudio nos ha permitido evidenciar que su exposición y crítica, es el resultado de una procesualidad reflexiva de crítica de las categorías y su apariencia, de herencia hegeliana. Al igual que en Doctrina

47 HARVEY, David. Para entender O Capital. São Paolo: Boitempo, 2013. p.47.

48 MARX, K. O capital: crítica da economía política. São Paolo: Boitempo. 2013.p.146.

49 MARX, K. O capital: crítica da economía política. São Paolo: Boitempo. 2013.p.156.

\begin{tabular}{|l|l|l|l|l|}
\hline Q Povista Dialectus & Ano 9 & n. 19 & Agosto-Dezembro 2020 & p.51-72 \\
\hline
\end{tabular}


de la Esencia esta propiedad será también llevada a sus últimas consecuencias continuando su determinación ${ }^{50}$. No obstante, al objetivo de este análisis nos muestra que el Fetichismo, en la redacción del Capital no es solo una exposición fenoménica sino, un método de crítica progresiva de los procesos y categorías.

\section{Consideraciones finales.}

El presente trabajo nos ha permitido evaluar el carácter central del Fetichismo en la crítica de Marx al Capital. Este se desdobla como proceso de producción de subjetividad, regla social de ocultamiento de las relaciones sociales de producción de la vida. Su crítica en la redacción final del Capital asume el fetichismo no como falsedad idolátrica sino como proceso ontológico de negación del otro y su antagonismo.

Al mismo tiempo en el presente se articuló una búsqueda de los elementos analíticos que la Teoría del Aparecimiento de Hegel aporta a una crítica de la apariencia. En ella se percibe una lógica reflexiva basada en una necesidad lógica auto-subsistente. La misma supone un análisis crítico de las categorías a partir de su desarrollo genético movidas por la contradicción que le es propia. Ello deslinda cualquier reducción de lo real a un formalismo lógico. Por el contrario, supone la producción de un pensamiento que al tiempo que se piensa a sí mismo, piensa la realidad.

Análisis a partir del cual evidenciamos la presencia de esta herencia lógica en la exposición de Marx del proceso de producción de la mercancía. Este aplica una lógica reflexiva al proceso de producción de la mercancía. Sin su comprensión el Fetichismo queda reducido a una explicitación fenomenológica de un proceso capitalista. En sentido contrario hemos valorado como evidenciando la herencia hegeliana, puede valorarse este como método de crítica de la apariencia. El mismo permite su desarrollo como medio de reflexión crítica tanto del propio pensamiento como de los procesos de negación subjetiva propia de la reproducción del capital. Al mismo tiempo supone una lógica reflexiva aplicable, en su dimensión crítica, a los procesos de producción de subjetividad. Con ello aportaría a una crítica de los determinismos económico-productivos de una parte de la tradición marxista y del modelo neoliberal dominante.

50 MOSELEY, Fred; SMITH, Tony (Orgs.). Marx's Capital and Hegel's Logica reexamination. Leiden; Boston: Brill, 2014. p.224.

\begin{tabular}{|l|c|c|c|c|}
\hline Conita Dialectus & Ano 9 & n. 19 & Agosto-Dezembro 2020 & p. 51-72 \\
\hline
\end{tabular}




\section{Bibliografía.}

ADORNO, Theodor W. Theodor W. Adorno sobre Marx y los conceptos fundamentales de la teoría sociológica. A partir de los apuntes del seminario del semestre de verano de 1962. Constelaciones. Revista de Teoría Crítica, 2017, vol. 8, no 8-9, p. 419-430.

ADORNO, Theodor W. Sobre Marx y los conceptos fundamentales de la teoría sociológica. A partir de los apuntes del seminario del semestre de verano de 1962. En: HANS-GEORG BACKHAUS en un apéndice a su obra Dia-lektik der Wertform. Untersuchungen zur marxschen Ökonomiekritik. $2^{\text {a }}$ ed., Freiburg i.Br.: çaira, 2011.

ALTHUSSER, Louis. Lire le Capital. Quadrige, Paris,1996.

ARTHUR, Christopher. La Lógica de Hegel y El Capital de Marx. Fred Moseley Editor Marx’s Method in Capital, Humanities Press: New jersey. USA, 1993.

BACKHAUS, H. -G. On the Dialectics of the Value-Form. Thesis Eleven.1980.

BAVARESCO, Agemir; LARA, Eduardo Garcia. Sistema e silogismo em O Capital. Veritas (Porto Alegre), 2017, vol. 62, no 1, p. 187-202.

BELLOFIORE Riccardo; REDOLFI RIVA Tommaso. The Neue Marx-Lektüre Putting the critique of political economy back into the critique of society. Radical Philosophy. jan/ feb 2015.

DUSSEL, Enrique. La producción teórica de Marx. Un comentario a los Gundrisse. 2da. Ed. Siglo XXI Editores. 1991.

Las Metáforas Teológicas en Marx. Editorial Verbo Divino. Navarra, 1993.

HARVEY, David. Para entender O Capital. São Paolo: Boitempo, 2013.

HEGEL Georg Wilhelm Friedrich. Ciencia Da Lógica: 2. A Doutrina da Essencia. Trad. Cristhian G. Iber; Federico Orsini. Petropolis, Rj: Vozes; Bragança Paulista: Editora Universitária São Francisco, 2017.

HENRICH, Michael. Crítica de la economia política. Una introducción a El Capital de Marx. Escolar y Mayo editores. 2008.

HINKELAMMERT, Franz J. Hacia una crítica de la razón mítica. El laberinto de la modernidad. Materiales para la discusión. San José: Arlekin, 2007.

IBER, Christian. Elementos da Teoria Marxiana do Capitalismo: um comentario sobre o livro I de O Capital de Karl Marx. Porto Alegre, RS: Editora Fi; EdiPUCRS, 2013.

Fundamento, condição e existência. Inédito. POA, 2019.

$\overline{\mathrm{POA}, 2019 .}$

A passagem para a $2^{\mathrm{a}}$ seção da lógica da essência: o aparecimento. Inédito.

\begin{tabular}{|l|c|c|c|c|}
\hline Qevista Dialectus & Ano 9 & n. 19 & Agosto - Dezembro 2020 & p. 51-72 \\
\hline
\end{tabular}


KOHAN, Néstor; GOPEGUI, Belén. Nuestro Marx. La Oveja Roja, 2013.

MARX, Karl. Manuscritos económicos filosófico. Edições 70. Lisboa, 1968.

Elementos fundamentales para la crítica de la economía política. Borrador 1857-1858. 15 ${ }^{\text {a }}$ Ed. Madrid: Siglo XXI. 1987.

O capital: crítica da economía política. São Paolo: Boitempo. 2013.

MOSELEY, Fred; SMITH, Tony (Orgs.). Marx's Capital and Hegel's Logic: a reexamination. Leiden; Boston: Brill, 2014.

ORSINI, Federico. A teoría do aparecimento na Lógica de Hegel. POA, 2019.

RAMAS San Miguel, Clara. Tesis Doctoral. Hacia una teoria de la apariencia: fetichismo y mistificación en la crítica de la economía política de Marx. Madrid, 2015.

. Sobre fetichismo y mistificación como formas de apariencia. Una lectura de la crítica de la economía política de Marx. Eu-topías: revista de interculturalidad, comunicación y estudios europeos, ISSN 2174-8454, Nº . 11, 2016.

\begin{tabular}{|l|l|l|l|l|}
\hline Revista Dialectus & Ano 9 & n. 19 & Agosto-Dezembro 2020 & p.51-72 \\
\hline
\end{tabular}

